\title{
EMOÇÕES MANIFESTAS PELO SER-MULHER-NO-MUNDO APÓS CIRURGIA CARDÍACA*
}

Thaís Vasconselos Amorim¹, Anna Maria de Oliveira Salimena², Maria Carmen Simões Cardoso de Melo²,

Ívis Emília de Oliveira Souza ${ }^{4}$

RESUMO: Este estudo teve por objetivo descrever as emoções desveladas no cotidiano de mulheres submetidas a procedimentos cirúrgicos de origem cardíaca. Utilizou-se a fenomenologia e a perspectiva de Martin Heidegger. Participaram do estudo 10 mulheres, pós-cirurgia cardíaca, de um município da Zona da Mata do interior de Minas Gerais, que realizaram seus depoimentos norteados pela questão: Como está o seu dia a dia após a cirurgia cardíaca? As mulheres manifestaram emoções expressas por choro, angústias e depressão, o que sinaliza a necessidade da consideração ontológica, traduzida a partir da linguagem de ruptura com o cotidiano saudável. Cabe ao enfermeiro dimensionar suas ações a partir do percebido, livre de suposições e pressupostos que impõem, frequentemente, um cuidado de enfermagem centralizado no profissional, em detrimento da premência do ser cuidado.

DESCRITORES: Cuidados de enfermagem, Emoções, Pesquisa qualitativa.

\section{EMOTIONS MANIFESTED BY THE BEING-WOMAN-IN-THE-WORLD FOLLOWING CARDIAC SURGERY}

ABSTRACT: This study aimed to describe the emotions revealed in the daily life of women who received cardiac surgery, using the Phenomenology and the perspective of Martin Heidegger. 10 women who had received cardiac surgery participated in the study, all from a city in the Zona da Mata in the state of Minas Gerais, who gave accounts guided by the question: What is your day-to-day like, following the cardiac surgery? The women showed emotions expressed through crying, distress and depression, which shows the need for ontological considerations, translated based on a language of breaking with the routine of health. It falls to the nurse to dimension her actions based on what is perceived, free of the suppositions and presuppositions which frequently impose nursing care centered on the professional, to the detriment of the urgency of the Being being cared for.

DESCRIPTORS: Nursing care, Emotions, Manifested emotions.

\section{EMOCIONES MANIFESTADAS POR EL SER-MUJER-EN-EL-MUNDO DESPUÉS DE CIRUGÍA CARDÍACA}

RESUMEN: Este estudio tuvo el objetivo de describir las emociones desveladas en el cotidiano de mujeres sometidas a procedimientos cirúgicos de origen cardíaco utilizándose la Fenomenología y la perspectiva de Martin Heidegger. Participaron del estudio 10 mujeres, poscirugía cardíaca, de un municipio de la Zona de la Mata del interior de Minas Gerais, que realizaron sus relatos norteados por la cuestión: ¿Cómo está su cotidiano después de la cirugía cardíaca? Las mujeres manifestaron emociones expresas por lloro, angustias y depresión, lo que sinaliza la necesidad de la consideración ontológica, traducida con base en el lenguaje de ruptura con el cotidiano saludable. Cabe al enfermero dimensionar sus acciones a partir de lo que percibe, libre de suposiciones y presupuestos que imponen, frecuentemente, el cuidado de enfermería centralizado en el profesional, en detrimento de la urgencia del ser cuidado.

DESCRIPTORES: Cuidados de enfermería, Emociones, Emociones manifestadas.

\footnotetext{
*Recorte da dissertação 'Os sentidos do ser-aí-mulher-após-uma-cirurgica-cardíaca sustentados em Heidegger: Implicações para a Enfermagem' apresentada ao Programa de Pós-Graduação da Universidade Federal de Juiz de Fora - UFJF, em 2013.

${ }^{1}$ Enfermeira. Mestre em Enfermagem.

${ }^{2}$ Enfermeira. Doutora em Enfermagem. Professora do Curso de Graduação e do Programa de Pós-Graduação em Enfermagem da UFJF. ${ }^{3}$ Enfermeira. Doutora em Enfermagem. Professora do Departamento Enfermagem Aplicada da Faculdade de Enfermagem da UFJF.

${ }^{4}$ Enfermeira. Doutora em Enfermagem. Professora do Departamento de Enfermagem Materno-Infantil da Escola de Enfermagem Anna Nery da Universidade Federal do Rio de Janeiro. Membro do Núcleo de Pesquisa em Enfermagem em Saúde da Mulher.
} 


\section{INTRODUÇÃO}

Considerada de grande porte, a cirurgia cardíaca incorre em técnicas cada vez mais avançadas e direcionadas para um período de pós-operatório em que as complicações sejam minimizadas ${ }^{(1)}$. Entretanto, a reação do ser humano é permeada de sentimentos e angústias. Em todas as etapas desse processo, o enfermeiro deve participar ativamente, angariando conhecimentos específicos para direcionar o cuidado de enfermagem no sentido de atender o outro na amplitude de suas dimensões.

Quando internado, o paciente pode contar com a assistência multiprofissional em setores diversos pelos quais adentra. Porém, ao aproximar-se o momento da alta hospitalar, experimenta dúvidas quanto aos cuidados que irá desenvolver no domicílio(2). Assim, torna-se imperiosa desde a admissão, a adoção de um plano de alta hospitalar que oriente o cliente/familiares/acompanhantes acerca das questões relativas ao autocuidado a ser desenvolvido posteriormente.

O medo e a ansiedade são alguns dos sentimentos vivenciados no momento da alta. A insegurança quanto à realização dos cuidados em suas residências ${ }^{(3)} \mathrm{e}$ as limitações corporais advindas da cirurgia, são exemplos de respostas passíveis de julgamento clínico pelo enfermeiro e intervenção conjunta dos profissionais da atenção primária e secundária. Evidencia-se um deficit importante nas orientações de enfermagem quando da alta hospitalar ${ }^{(4)}$. Neste momento, o enfermeiro utiliza-se de termos técnicos, com orientações múltiplas e repasse de informações verbais, muitas vezes incompreendidas pelo paciente/familiares/acompanhantes, 0 que incorre na possibilidade de $\operatorname{erros}^{(3)}$.

Quando orientados e avaliados antes da saída hospitalar por enfermeiros que estiveram com os pacientes nas consultas, evidenciou-se menor ansiedade e depressão após seis meses de acompanhamento ${ }^{(5)}$, o que denota a relevância de reflexões sobre os retornos para consultas de enfermagem após a intervenção cirúrgica.

A mulher responde de modo mais impactante que o homem aos fatores de estresse provocados pela vivência de procedimentos cirúrgicos de origem cardíaca. Nelas, há menor senso de coerência e, portanto, torna-se necessário apoio profissional no que tange ao aumento da autoestima e segurança, auxiliando-as nos modos de lidar com o dia a dia que difere do que vivenciavam anteriormente ${ }^{(6)}$.
Diante do vivido profissional em unidades de pós -operatório de cirurgia cardíaca, foi possível perceber as emoções das mulheres a partir das expressões verbais de receio quanto ao futuro. Nestes momentos, era inevitável o movimento de se colocar no lugar do outro, dada a similitude de gênero e aproximação com a faceta dinâmica do ser-mulher. Surgiram então inquietações em torno de como ela vivenciaria aquela situação? Quais emoções experimentaria no cotidiano após a alta hospitalar? Que papéis lhe caberiam então, diante da (im)possibilidade de ser ativa no mundo?

Diante destes questionamentos, estabeleceu-se como objetivo deste estudo descrever as emoções desveladas no cotidiano de mulheres submetidas a procedimentos cirúrgicos de origem cardíaca. A relevância de tal investigação constitui-se na contribuição para a atuação do enfermeiro desde o perioperatório até o domicílio, compreendendo o cuidado de enfermagem de modo integral. Tal objeto de estudo encontra apoio epistemológico nas ciências interrogativas que respondem à esfera física, porém são lacunares quanto aos aspectos de natureza psicossocial. Por isso optou-se por utilizar a Fenomenologia na perspectiva de Martin Heidegger, que busca a descrição dos fenômenos, sem a intenção de interpretá-los, compreendendo a indissolubilidade entre o objetivo e o subjetivo do ser do humano( ${ }^{(7)}$.

\section{Referenciais filosófico e metodológico: a Fenomeno- logia na perspectiva Heideggeriana}

A Fenomenologia surgiu no início do século XX, na Alemanha, com Edmund Husserl, influenciado pelas ideias de Platão, Descartes e Brentano. Destacam-se como pensadores fenomenólogos apoiados nas concepções de Husserl: Martin Heidegger, Alfred Schutz, Jean-Paul Sartre e Maurice Merleau-Ponty ${ }^{(8)}$.

Os dados imediatos da consciência, a raiz de que se nutre é o ponto de partida da Fenomenologia, busca o conhecimento do fenômeno e seus significados essenciais de modo interrogativo, radical e inacabado. $\mathrm{O}$ fenômeno é tudo aquilo que aparece à consciência, daquilo que é dado, buscando explorá-lo ${ }^{(8)}$. O que se percebe, em que se pensa, do que se fala, o que conjuga o fenômeno com o ser de que é fenômeno, como sobre o que une com o eu para quem é fenômeno ${ }^{(7)}$. Heidegger compreende o ser como pre-sença, o manifesto, o percebido, o compreendido e o conhecido para “o ser-aí” ou Dasein. O Dasein então é presença no mundo e sendo no mundo, compreende-se como ser de possibilidades ${ }^{(7)}$. 
O Método Heideggeriano consiste em duas fases principais. O primeiro momento metódico da analítica existencial, que é a compreensão vaga e mediana, constitui-se a partir da expressão de vivências pelos depoentes, também denominados entes privilegiados em suas facetas ônticas. Após a elaboração do fio condutor $^{(9)}$ através das unidades de significados pode-se construir o conceito do vivido ${ }^{(7)}$.

A hermenêutica em Heidegger é representada pela interpretação do significado que o ser confere àquilo que lhe foi interrogado, denotando o aspecto ontológico do ser sendo-no-mundo ${ }^{(7)}$.

\section{MÉTODO}

A Fenomenologia fundamentada no pensamento de Martin Heidegger subsidiou este estudo que aconteceu em um hospital de médio porte da Zona da Mata do interior de Minas Gerais. Sob o parecer número $304 / 2011$, esta pesquisa foi aprovada no Comitê de Ética em Pesquisa da Universidade Federal de Juiz de Fora e obedeceu aos preceitos de pesquisas com seres humanos de acordo com a Resolução 196/96(10).

O período da etapa de campo compreendeu os meses de dezembro de 2011 e janeiro de 2012, constituindo-se participantes 10 mulheres que iniciaram seus depoimentos após a questão: Como está o seu dia a dia após a cirurgia cardíaca? Os critérios de inclusão foram estar na faixa etária superior a 18 anos e com mais de três meses da alta hospitalar, por este estudo considerar o cotidiano melhor apreendido após o pós-operatório tardio e alta médica.

Apresentou-se a cada mulher a possibilidade de escolha do pseudônimo da flora brasileira a fim de garantir o anonimato e ao mesmo tempo aproximá-las da simbologia feminina, que estava contida nesta proposta.

Os depoimentos foram gravados em dispositivo Mp3, transcritos integralmente logo após cada encontro e colhidos até o momento em que não mais se observou informações diferenciadas. Também se utilizou um diário de campo, com vistas às anotações notadas pela pesquisadora, especialmente aquelas que se referiam à linguagem não verbal.

Na análise, após leituras e escutas atentivas, emergiram as estruturas essenciais ${ }^{(8)}$ que culminaram nas unidades de significados, a partir da convergência das falas das depoentes, possibilitando aproximar os modos de ser da mulher em seu dia a dia após uma cirurgia cardíaca.

\section{RESULTADOS}

Neste artigo é apresentada uma das cinco unidades de significados apreendidas, seguidas de alguns recortes dos depoimentos que a originou. As mulheres no dia a dia após uma cirurgia cardíaca apresentam-se emotivas e assustadas, como apresentado.

[...] tem dia que eu sinto, assim, parece que meu sentido vai embora, foge, entendeu? Eu sinto assim, angústia... Sinto depressão. E tem dia que me dá uma vontade de chorar, choro à toa sem saber por que. E [...] ai eu fui notando, eu acho que eu tô com depressão [...]. (Rosa)

[...] é, depois assim que eu operei, que eu vim embora pra casa, que eu fiz a primeira consulta com o doutor, é que eu assustei [...]. Assim, assistindo ele falando, que ele dá aula, né, então quando eu vou consultar, ele dá aula, ele dá aula pros alunos dele comigo. Ai eu vinha com aquilo meu Deus. 'Ai tiramos o coração, aí fizemos, botamos a safena'. Ai eu vinha de lá [...] meu Deus. Aí eu comecei, aquilo começou a me deprimir uт роисо [...].(Violeta)

[...] eu fiquei um pouco abalada, fiquei um pouco triste, fiquei um pouco depressiva, por que precisava de todo mundo. Eu fiquei bem assustada na hora que eu vim pra casa, eu fiquei, ah, como eu vou te explicar [silêncio] eu fiquei assustada por causa da cicatriz [...]. (Bromélia)

[...] quando eu voltei do hospital eu senti uma emoção muito grande de tá de volta em casa, emoção feliz de tá ali, passar o que passou e voltar, graças a Deus tô em casa. Todo mundo estava esperando no portão, alegre. Eu vou me sentindo bem [...]. (Hortência)

[...] eu acho que eu fiquei assim mais emotiva, eu acho. É, se eu não puder expressar qualquer coisa que me manifesta, por exemplo, se eu estou chateada com alguma coisa, eu não posso falar, ai eu choro. Eu não era assim, eu falava mais do que chorava, agora eu choro mais do que falo. Não sei explicar por que, eu sinto aquela pressão, sabe, aquela coisa, ai eu choro, desabafo [...]. (Orquídea)

[...] ah, quando voltei pra casa, fiquei muito triste, pensando muita coisa: 'Ai meu Deus do céu, será que eu vou sair dessa?' (Lírio)

[...] eu sou emotiva, qualquer coisa me abala, enten- 
deu? Olha, eu tenho alegria sim, mas parece que saiu um pouco disso, não sei se é medo, mas não é como eu era antigamente não, me retraí mais, estou mais retraída. É gozado, eu falo assim: 'Foi tão de repente!' Entende? Foi assim um susto! (Ipê amarelo)

[...] eu estou mais emotiva prá algumas coisas, mas estou forte também. Eu acho que eu to mais preparada do que nunca, mais forte, porém, mais emotiva [...]. (Ipê roxo)

[...] e eu ainda tenho um agravante, fez dois anos que eu perdi meu marido, sabe? Isso mexe muito, a saudade ainda tá agarrada comigo, a gente era muito junto, muito perto um do outro e essa ausência é muito difícil. Ai, conviver com os problemas físicos e os da alma [...]. (Begônia)

\section{DISCUSSÃO}

A compreensão vaga e mediana, primeiro momento metódico da analítica Heideggeriana, possibilita ao investigador

decidir o que significa essa compreensão de ser obscura e ainda não esclarecida e quais espécies de obscurecimento ou impedimento são possíveis e necessárias para um esclarecimento explícito do sentido do $\operatorname{ser}^{(7: 41)}$.

Assim, a mulher entendida como ente interrogado, significou como se sentia no dia a dia após uma cirurgia cardíaca. Estes significados revelaram o modo de ser cotidiano das mulheres, onde na maior parte das vezes, elas se encontravam. A partir das suas manifestações, foi possível construir a visão prévia, compreendendo-as nos aspectos ônticos, factuais ${ }^{(7,10)}$, discutidos a seguir.

As mulheres se consideraram mais emotivas no cotidiano. As emoções se evidenciaram em choro, angústias e depressão. Também experimentaram sentimentos de gratidão por estarem de volta, vivas e bem. Expressaram tristeza sem saber explicar a causa, choravam sem saber por que e comentaram o fato de que a dependência alheia fazia com que se sentissem entristecidas. Ao relatarem tal situação a seus médicos, estes as encaminham ao psiquiatra, porém, elas se negavam a fazê-lo o que justificavam com a preocupação da possibilidade de dependência medicamentosa, além de se sentirem fortes o bastante para saírem sozinhas de tal situação.

Os enfermeiros lidam a todo instante com o ser permeado por subjetividades e que pode se encontrar em situação de doença ou se recuperando de um agravo à saúde. As singularidades que envolvem os fenômenos vivenciados pelos pacientes transcendem a lógica técnico-científica. Portanto, o cuidado de enfermagem deve ser atentivo às múltiplas dimensões e facetas humanas, buscando a possibilidade de alcançar o sentido que funda o que se manifesta ${ }^{(11)}$.

As mulheres relatavam que a alegria de antes não permeava a realidade atual, movimentando-as em direção ao retraimento em um modo de autodefesa que as auxiliava na lide cotidiana de convivência com os "problemas do corpo e da alma". Parte da emotividade expressada girou em torno do positivo, da alegria e satisfação de estarem vivas e recuperadas de uma grande cirurgia que é temida por muitos. Verbalizavam que o acolhimento em suas chegadas foi confortador. Sensibilizavam-se mais no presente, entretanto sentiam-se fortes para o enfrentamento das diversas situações que a vida lhes apresentava.

Ao ser-com a mulher em quaisquer das esferas de atenção, o enfermeiro assume a responsabilidade de integralizar o cuidado, que deve estar embasado nos princípios de prevenção, promoção, proteção e recuperação à saúde. O Sistema Único de Saúde apoia-se na perspectiva de um profissional que supere as expectativas da demanda, ao desenvolver uma prática assistencial centrada na interação com o paciente a partir da escuta ${ }^{(12)}$.

As mulheres mencionavam que se sentiam assustadas diante de várias ocorrências, desde o relato de situações em que, na presença delas, médicos descreviam detalhadamente para seus discentes os procedimentos cirúrgicos, até o espanto provocado pela cicatriz, fosse pelo tamanho ou secreção exteriorizada. Rememoravam o susto que levaram quando da notícia da necessidade cirúrgica e das situações que no dia a dia as colocavam próximas da possibilidade de novas intervenções.

O temor é

um dos modos de ser da pre-sença no cotidiano e se dá no fenômeno da disposição, esta, referida por Heidegger, como o "humor" ou um "estado de humor que tem conotação relacional de integração e reação com os modos de afeto e de sentimen$\operatorname{tos}^{(13: 123)}$.

Como o agir inautêntico está presente na cotidia- 
neidade e o voltar-se a si mesmo possui o caráter de ameaça, o ser disponibiliza-se para o temor, um modo impróprio e ôntico em que se teme um ente intramundano que circunda o ente ${ }^{(14)}$. Neste modo, a mulher revela a possibilidade da angústia diante do espanto, compreendido como algo que nos causa admiração. Ontologicamente, a angústia remete à possibilidade de sair da estabilidade cotidiana em direção ao fenômeno original, "primordial para a posição do homem frente aos acontecimentos que lhes advém em sua relação com o mundo"(15:4).

Em face desta realidade, a Enfermagem, como ciência do cuidado ao outro, deve aproximar-se do ente que se cuida buscando o acesso ao Ser que ora obscurece, ora revela os sentidos da sua existência. O estabelecimento de um vínculo com a mulher cardíaca, que transcenda o aspecto biomédico e seja capaz de perscrutar as emoções que se manifestam em seu cotidiano, confere uma relação autêntica que utiliza o profissional como instrumento terapêutico e nesse sentido, valioso para a recuperação.

\section{CONSIDERAÇÕES FINAIS}

Compreender as emotividades da mulher a partir da compreensão vaga e mediana em seu dia a dia após uma cirurgia cardíaca possibilita ir além do aspecto ôntico expresso pela doença. Os resultados apontam para a necessidade da consideração ontológica, traduzida a partir da linguagem de ruptura com o cotidiano saudável, anterior ao processo saúde-doença. Neste ínterim, cabe ao enfermeiro dimensionar suas ações a partir do discurso do paciente, livre de suposições e pressupostos que impõe, frequentemente, a assistência de enfermagem centralizada no profissional, em detrimento da premência e necessidades do ser cuidado.

É relevante a discussão sobre as ações de preparo para a alta, referência e contra referência entre os enfermeiros dos diversos níveis de atenção, em busca da assistência integralizada que o Sistema Único de Saúde preconiza, com vistas a reduzir a fragmentação do processo de cuidado à saúde do ser humano, observada e pretendida na atualidade.

Diante desta realidade, buscou-se ampliar a percepção acerca da interface entre o profissional e o paciente, mediada pelo pensamento fenomenológico de Martin Heidegger que possibilita ao enfermeiro um movimento de abertura compreensiva e solidária em direção ao paciente que significa seu existir profissional.

\section{REFERÊNCIAS}

1. Cavalcanti ACD, Coelho MJ. Ways of care in cardiac surgery. R. pesq.: cuid. fundam. online. [Internet] 2011;3(4) [acesso em 14 jul 2012]. Disponível: http://www.seer.unirio.br/ index.php/cuidadofundamental/article/view/1399/pdf_462

2. Almeida PFP, Júnior RG, Gasparino RC. Dúvidas dos pacientes em pós-operatório de revascularização do miocárdio. Cogitare enferm. 2009;14(4):675-81.

3. Carvalho ARS, Matsuda LM, Stuchi RAG, Coimbra JÂH. Investigando as orientações oferecidas ao paciente em pósoperatóriode revascularização miocárdica. Rev. Eletr. Enf. [Internet]. 2008;10(2) [acesso em 20 jul 2012]. Disponível: http://www.revistas.ufg.br/index.php/fen/article/view/8062

4. Pompeo DA, Pinto MH, Cesarino CB, Araújo RRDF, Poletti NAA. Nurses' performance on hospital discharge: patients' point of view. Acta Paul. Enferm. 2007;20(3):345-50.

5. Lima FET, Araújo TLD, Serafim ECG, Custódio IL. Nursing consultation protocol for patients after myocardial revascularization: influence on anxiety and depression. Rev. Latino-Am. Enfermagem. 2010;18(3):331-8.

6. Torrati FG, Gois CFL, Dantas RAS. Strategy in the care of cardiac surgical patients: evaluation of the sense of coherence. Rev Esc Enferm USP. [Internet]. 2010;44(3) [acesso em 15 jul 2012]. Disponível: http:// dx.doi.org/10.1590/S0080-62342010000300027.

7. Heidegger M. Ser e tempo. São Paulo (SP): Vozes; 2011.

8. Silva JMO, Lopes RLM, Diniz NMF. Fenomenologia. Rev Bras Enferm. 2008;61(2):254-7.

9. Salimena AMO, Souza IEO. Daily-life of women after histectomy supported by Heidegger's thought. Rev Bras Enferm. 2010;63(2):196-202.

10. Paula CC, Souza IEO, Cabral IE, Padoin SMM. Movimento analítico-hermenêutico heideggeriano: possibilidade metodológica para a pesquisa em enfermagem. Acta Paul. Enferm. 2012;25(6):984-9.

11. Boemer MR. A fenomenologia do cuidar: uma perspectiva de enfermagem. In: Peixoto AJ, Holanda AF. Fenomenologia do cuidado e do cuidar: perspectivas multidisciplinares. Curitiba: Juruá; 2011. p. 61-6.

12. Lucchese R, Vera I, Pereira WR. As políticas públicas de saúde: SUS como referência para o processo ensinoaprendizagem do enfermeiro. Rev. Eletr. Enf. [Internet]. 
2010;12(3) [acesso em 15 jul 2012]. Disponível: http:// dx.doi.org/10.5216/ree.v12i3.11144

13. Melo MCSC. Mulheres em risco familiar para o câncer de mama: uma hermenêutica da prevenção secundária [tese]. Rio de Janeiro (RJ): Escola de Enfermagem Anna Nery, Universidade Federal do Rio Janeiro; 2009.

14. Amorim TV. Os sentidos do ser-aí-mulher-apósuma-cirurgia-cardíaca sustentados em Heidegger: implicações para a enfermagem [dissertação]. Juiz de Fora (MG): Universidade Federal Fluminense; 2013.

15. Sousa, CM. O fenômeno da ambiguidade no pensamento de Martin Heidegger. Existência e Arte. 2007;3(3):1-7. 